\title{
Minimally invasive thermal brain treatment
}

Paul Morrison, Terence Wong

Paul R. Morrison, Terence Z. Wong M.D., "Minimally invasive thermal brain treatment," Proc. SPIE 10297, Matching the Energy Source to the Clinical Need: A Critical Review, 1029709 (24 January 2000); doi: 10.1117/12.375229 


\title{
Minimally invasive thermal brain treatment
}

\author{
Paul R. Morrison ${ }^{* a}$ and Terence Z. Wong ${ }^{\ominus b}$ \\ ${ }^{a}$ Harvard Medical School, Harvard Medical Laser Center, Boston, MA \\ ${ }^{b}$ Duke University Medical Center, Dept. of Radiology, Durham, NC
}

\begin{abstract}
From a reading of recent neurosurgical literature with a search focus on intracranial applications, a list of thermal agents and related minimally invasive techniques was drawn; this list was supplemented by our own research experience. Thermal agents which are either implemented in clinical practice or undergoing active research include: radiofrequency current, laser light, microwave electromagnetic radiation, ultrasound and cryogens. Therapies include percutaneous coagulation of small targets which are less than half of one cubic centimeter as for rhizotomy for trigeminal neuralgia and pallidotomy for kinetic disorders, as well as interstitial hyperthermia and/or coagulation of large tumors which range up to centimeters in diameter. Implementation of a thermal agent for therapy evolves in a dynamic interaction between the specific technology and an understanding of the tissue properties governing the agent's therapeutic effect. Minimally invasive techniques require methods to define, visualize and approach targeted tissue, and to monitor (and thereby control) the extent of the thermal 'lesion.' Over the twentieth century, concomitant with advances in neurosurgery and radiology, technologies have been developed with which to approach the twenty-first century in pursuit of these minimally invasive thermal interventions which are, as of yet, new and underdeveloped.
\end{abstract}

Keywords: surgery, radiofrequency, laser, microwave, ultrasound, cryotherapy, hyperthermia, coagulation, image-guided, MRI.

\section{INTRODUCTION}

In addressing the topic of minimally invasive 'thermal brain treatment', this review considers the intracranial use of thermal 'agents' to relieve disease. These agents are destructive to cells (typically by coagulation or effects secondary to hyperthermia). Generally, by confining this destruction to a 'target' (thus achieving the desired therapeutic effect) and minimizing the damage inflicted to non-targeted structures, the treatment can be considered 'minimally invasive.' The agents listed below are those currently in clinical practice or are being researched in human studies or on the lab bench.

A contemporary list of relevant thermal agents for intracranial applications includes:

Radiofrequency (RF) Current

'Optical' Electromagnetic Radiation (EM) - LASER light

Microwave (MW) EM Radiation

Ultrasound

Cryogens

\footnotetext{
* Correspondence: eddress: paul morrison @ hms harvard.edu- phone: (617) 432-2003

- Correspondence: Matching the Energy Source to the Clinical Need: A CFilical Review, edited by Thomas P. Ryan,

CCC code: $0277-786 X / 17 / \$ 18 \cdot$ doi: $10.1117 / 12.375229$

Proc. of SPIE Vol. 10297 1029709-1
} 
Matching the Energy Source to the Clinical Need / 173

The order of the list given above is related primarily to the prevalence of an agent's clinical application to target tissues within the cranial vault. The order is secondarily related to the attention given the research of an agent (again, for intracranial application) as evident in the literature.

\subsection{Technology and tissue}

Generally, these agents (as surgical tools) are products of the twentieth century. The devices which deliver these energies to tissue have developed through: a) technological mastery, and b) understanding of energy-tissue interactions which have both grown over that same time period. As two examples, consider that the first electrosurgical unit was introduced in the 1910s or that the first laser available for medical applications appeared in the 1960s (the ruby laser at $694 \mathrm{~nm}$ ). In order to invent a suitable device, implement it and optimize its performance (in answering a clinical surgical need) the requisite knowledge base extends beyond producing the energy to the tissue-interaction.

\subsubsection{Technology and tissue: example 1, electrocautery}

Returning to the first example, the Bovie electrosurgical unit (ESU) of the 1920s used a spark-gap generator to produce alternating current in the form of damped irregular waveforms at a frequency of approximately $1 \mathrm{MHz}$ (radiation in the radio region of the EM spectrum). ${ }^{1}$ Itself was a redesign over the ESU of the previous decade which relied on excessive voltages. With the addition of a resonating circuit, the Bovie was able to cut tissue as well as coagulate. This found immediate intracranial application for control of bleeding during tumor resection through a craniotomy.

The system used an "active electrode" and a grounding pad attached to the patient to complete the electrical circuit. High alternating current densities at the fine tip of the active electrode coagulated tissue (the "dispersive" grounding pad was suitably broad to keep current densities low). As suggested above, understanding the energy-tissue interaction for this specific agent was important to the acceptance of the ESU - i.e. the Bovie's predecessor's high voltage had too high an impact on tissue. With time, clinical experience and tissue science fed back to device design. Consider that it was determined by experiment that direct current and low frequency alternating current did not produce acceptable coagulation - inducing excessive muscle stimulation and hazardous electrolysis at the electrodes (sometimes "local flame burning at points of sparking"). These problems were found to be generally absent at frequencies above $100 \mathrm{kHz}$. And it was learned that the range of $550-1600 \mathrm{kHz}$ corresponded to macromolecular resonance.

Further, it was established that current could traverse through blood vessels and neural structures. This conduction could deposit thermal effects remote to the surgical field. Accordingly, this "monopolar" set-up is not used for surgery near the spinal cord or brainstem. In part, this conduction issue prompted the development of "bipolar" RF coagulation (achieved separately by Greenwood and Malis). Bipolar forceps supplied current between the tips of the surgical forceps. This had a much lower tissue impedance (resistance) than that of monopolar (150 ohms vs $1500 \mathrm{ohms}$ ) and enabled $5-10 \%$ of the power to provide coagulation without the remote heating. The bipolar forceps are now a mainstay of neurosurgery for tumor resection, while both monopolar and bipolar RF ESUs have prominent roles in the operating room for cutting and coagulating. Also, advances in materials science (for electrode development) and electronics (customizing waveforms to optimize coagulation; circuit isolation for safety; grounding for efficiency) 
played key roles in the improvement of control of the deposition of the RF energy for the desired effect - reduction of blood in the surgical field.

\subsubsection{Technology and tissue: example 2, the laser}

The introduction of the ruby laser marked the beginning of a score of new devices for medical applications. The invention of new lasers and optical technologies for surgery and medicine have grown in parallel with the improvement of science's understanding of the physical characteristics of tissue which govern light-tissue interactions.

The ruby was quickly followed by other lasers including the carbon dioxide $\left(\mathrm{CO}_{2}\right)$, neodymium yttrium aluminum garnet (Nd:YAG), argon (Ar) and the potassium titanyl phosphate (KTP). While lasers other than these have been developed and used in medical applications, these provide a suitable perspective of the topic. The names for these lasers identify the lasing 'medium' involved in generating the light. The medium is used in the process of light amplification by stimulated emission of radiation (L.A.S.E.R.). The energy spacing of the electronic transitions of the atoms or molecules of the medium determines the frequency of the light. In medical applications, it is more common to use the wavelength to characterize the light. The laser light is energy in the form of EM radiation. The lasers named above span a range of the EM spectrum from the visible to the invisible infrared. i.e. The Ar laser has two strong emission lines in the blue at 488 $\mathrm{nm}$ and the green at $514 \mathrm{~nm}$ (either or both of which may be used from a medical unit); the KTP laser (actually a 'frequency doubled' Nd:YAG) emits in the green at $532 \mathrm{~nm}$; the ruby laser emits in the red at $694 \mathrm{~nm}$; the Nd:YAG emits invisibly in the near infrared at $1064 \mathrm{~nm}$, and the $\mathrm{CO}_{2}$ emits invisibly in the far infrared at $10,600 \mathrm{~nm}$.

While the invention of each of the lasers provided a new agent for medical use, the actual evolution of their utility in neurosurgery depended on the interaction of the light and tissue - on the characteristics of tissue as pertains to light and heat. ${ }^{2-7}$ In considering the wavelengths of light from the lasers listed above: the blue, green and red are poorly absorbed by water (a primary constituent of tissue), however, the green wavelengths are near peaks in the absorption spectra of oxyhemoglobin (a primary component of blood). Further, the $1064 \mathrm{~nm}$ light of the Nd:YAG is less absorbed by blood than green by nearly a factor of ten. Water absorption is a factor at Nd:YAG's $1064 \mathrm{~nm}$, but the water absorption of the $\mathrm{CO}_{2}$ 's $10,600 \mathrm{~nm}$ light is 1000 times as great.

Accordingly, while the the lasers listed have been tested in brain tissues, generally, the $\mathrm{CO}_{2}$ has been most favored and has an ongoing presence in the neurosurgical operating room. It is used primarily for tissue resection or tumor debulking through a craniotomy. Overall, it is the high absorption of the 10,600 nm light by the tissue that helps to limit the extent of thermal damage below the surface. This allows a thermal cutting through tissue with some coagulation thus reducing bleeding in the surgical field (though large vessels can require coagulation by RF bipolar forceps). Some added penetration of the coagulative effect of the $\mathrm{CO}_{2}$ can be achieved by prolonging the duration of the light exposure which allows for the heat to conduct from the surface. For the wavelengths of the other lasers listed above, the optical penetration into brain tissue is too great (on the order of severla millimeters; due to the low absorption and also high scattering) to control the subsurface effect; this is not optimal in light of the intricacies of the anatomy. (Notably, for fine resection through a craniotomy, the need is to limit the thermal damage; in contrast, interstitial laser therapy of tumors generally requires maximal penetration into tissue and for which the Nd:YAG laser has been highly utilized.) 
Important in the medical device development and engineering for laser applications is that the visible and near IR wavelengths can be transmitted by optical fibers from the laser aperture to the surgical field. However, the $\mathrm{CO}_{2}$ light (due to high absorption by quartz) cannot be transmitted by a fiber. Thus, it is typically transmitted by a series of reflecting mirrors housed in an articulating arm. For neurosurgery, the articulating arm is usually connected to an operating microscope to give good visualization of the surgical field.

As described in the two examples, there is an ongoing dynamic between the engineering of the techniques for delivery of the thermal agents listed at the outset in this introduction and the understanding of the tissue properties which govern the interaction and effectiveness of the agent for the desired clinical effect.

In the context of this review of thermal applications in the brain, the density of a tissue, its specific heat capacity, thermal conductivity and blood perfusion are important parameters in describing the flow of heat and the progression in time of the spatial profile of heat after energy has been deposited and absorbed. Accordingly, the absorption and scattering characteristics of the tissue play a role. In a theoretical analysis comparing the heat distribution in tissue of $1 \mathrm{MHz}$ ultrasound, $1 \mathrm{Ghz}$ microwave radiation and $810 \mathrm{~nm}$ light, Skinner and co-workers illustrated the influence of the relative values of key tissue parameters in determining the distribution of the energy and the subsequent heat profile. ${ }^{8}$ For the sources indicated, mathematical models of delivery devices with similar geometries showed that the penetration of the thermal effect in brain tissue is greatest with ultrasound, and greater with microwave radiation than light. Deep penetration can be a desired clinical effect. This was not the case for tumor resection through a craniotomy as seen above for which the goal was a spatially confined but effective coagulation of tissue, but deep penetration is applicable to hyperthermia or coagulation of large tumors.

To follow is a review of thermal agents (energy sources) used in current clinical applications and research studies which pertain to minimally invasive therapy in the brain. While some agents are used for the same clincal target, not all agents are utilized for all purposes. However, it is likely that the continued evolution through research and engineering of these technologies will place the full spectrum of agents in the hands of physicians in the coming years.

\section{INTRACRANIAL APPLICATIONS OF RF}

In general, it is not the brain per se which is the target of a thermal therapy, but rather a tumor. However, there are also non-tumor sites in the brain which can be targeted with a thermal agent to give relief from a disease state. Monopolar RF has been applied with success in the treatment of sharp facial pain attributed to trigeminal neuralgia; the target is a small bundle of nerve fibers. Also, in the case of hyperkinetic and hypertonic disorders such as seen with Parkinson's disease, the targets include small structures deep in the brain (the globus pallidosus and/or thalamus).

\subsection{RF for the treatment of trigeminal neuraglia}

The approach to relieve facial pain due to 'trigeminal neralgia' by injuring the trigeminal nerve (at the appropriate division of its root) has been known for many years. The nerve has three divisions: the ophthalmic, maxillary, and mandibular. These divisions are responsible primarily for sensation (though the mandibular nerve does function for both sensation and motion). The ophthalmic division serves the cornea, ciliary body, lacrimal gland, mucous membrane of the nasal cavity, skin of the forehead, eyelid, eyebrow and 
nose. The maxillary division serves the dura, forehead, lower eyelid, orbit, upper lip, gums, teeth of the upper jaw, skin of the cheek and nose. The mandibular division serves the temple, auricle of the ear, lower part of the face, teeth and gums of the mandible, mastication muscles, and mucous membrane on the anterior part of the tongue. The fibers of the sensory root arise from the semilunar ganglion; the fibers of the motor root arise from nucleus in the pons.

Therapeutic techniques to injure the nerve have included chemical rhizotomy (injection of chemicals intracranially) and RF 'ablation' at the trigeminal ganglion. An alarming incidence of side effects from the procedures motivated Sweet and Wepsic to pose that a more controlled thermal dose could be delivered. ${ }^{9}$ They surmised from the evidence of the day, that this would be advantageous over the relatively poor control of the spread of injected chemicals and excessive electrocoagulation. Their solution was to use less current and to coagulate incrementally to effect. They cited key improvements which assisted in the task. Particularly, they noted the availability of more controllable heat sources than the then current $\mathrm{RF}$ generators at $2 \mathrm{MHz}$. The procedure was performed percutaneously with a $10 \mathrm{~cm}$ long probe (active electrode) with an exposed tip 5 or 10 $\mathrm{mm}$ in length; the dispersive pad was located on the shoulder. With improved drugs for sedation, via a perforation through the cheek, a freehand search for the foramen ovale was performed. Once located with the tip of the probe, an x-ray was taken to confirm positioning. Further, in order to confirm location of the active length of the probe tip, an electrical stimulation was performed at the threshold of sensation. A thermal "test" lesion was made for sensation; response here further confirmed targeting of the trigeminal branches. Temperature was monitored at a single point on the probe and watch was kept on the voltage or current to confirm the condition of the probe (i.e. an unusually high voltage to maintain a set temperature might indicate coagulum or a defective probe). Temperatures were kept at approximately $60^{\circ} \mathrm{C}$. Of 274 patients treated, 187 received relief from pain, but maintained sensation in the skin - an advance due to their conservative approach. Elementary to their hypothesis under which they worked was that the smaller myleniated or unmyelinated nerves were more susceptable to thermal damage than the more heavily myelinated nerves.

Around the same time, Hori and co-workers performed "controlled thermocoagulation" of the facial nerve for treating facial spasm using a different percutaneous approach. ${ }^{10} \mathrm{~A}$ flouroscopic technique was used to guide the $\mathrm{RF}$ probe through the stylomastoid foramen with confirmation by electrical stimulation. A first lesion was made at $55^{\circ} \mathrm{C}$ for $10 \mathrm{sec}$. The temperature was then raised to between $60-65^{\circ} \mathrm{C}$, and repeated until a slight facial weakness was observed. Most patients experienced a transient facial weakness for up to 4 months, but 24 of 27 patients were spasm free at 1.5 years post-operatively.

In 1983, Cosman and co-workers in reviewing technology for "localized therapeutic destruction of nervous tissue" which was deemed successful as there were mechanisms 1) by which to monitor the temperature and thus to "quantify lesion size" and to prevent charring or boiling ... and 2) which provided "excellent target localization using stimulation, impedance monitoring, and recording." "The report stated that brain tissue is damaged at temperatures at and above $45^{\circ} \mathrm{C}$ which is a lower threshold for effect than the typical coagulation threshold for proteins of $60{ }^{\circ} \mathrm{C}$. The lesion size was most dependent on the temperature and size of the RF probe tip, and the size equilibrated after only $30-60 \mathrm{~s}$. The lesions created were ellipsoidal and less than $1 \mathrm{~cm}$ in length and diameter. Some lesions showed evidence of tending toward the ventricles which was taken as an indication that a path of least resistance for the current and heat. 
In current literature, Taha and Tew published on their experience with 500 patients treated with percutaneous RF rhizotomy for trigeminal neuralgia. ${ }^{12}$ They proposed also that the technique is based on the premise that RF lesions are selective to the trigeminal "nociceptive pain fibers" (i.e. the unmyelinated C fibers and poorly myelinated A-delta fibers) and it preserves the trigeminal heavily myelinated fibers which carry tactile prorioceptive and motor functions. ${ }^{13,14}$ They noted that current (1996) percutaneous techniques include: RF, glycerol injection and balloon compression. ${ }^{12}$ The procedure was performed under conscious intravenous sedation. The goal of the therapy was the "dense hypalgesia in the painful trigger zone" which they defined as a $2 / 3$ loss of pinprick perception providing pain relief to the patient. They recalled the possible side effects of the procedure: facial numbness, dysesthesia, corneal anesthesia, keratitis, trigeminal motor dysfunction, permanent cranial nerve deficit, intracranial hemorrhage and others. They reported that the highest rate of initial pain relief was for technically successful RF procedures with a $20 \%$ rate of pain recurrence within 9 years which is a comparable rate to surgical microvascular decompression and a more favorable rate than glycerol injection rhizotomy. With RF therapy, facial numbness was typically encountered though usually mild and well-tolerated. They reported having used a careful technique to target the specific trigeminal rootlets and to limit degree of sensory deficit (major dysesthesia incidence was $2 \%$ ). If the patient could not assist during the procedure to "localize or quantify" the lesion, the surgeon needed to use personal observation, physiological monitoring or sensory evoked potentials. They cited "improved precision and reduced side effects" using a curved electrode (as opposed to straight). The lesion was better controlled with $\mathrm{RF}$ than glycerol or balloon compression, and the thermal damage perhaps more effective and not as morbid as the other modalities.

As a postscript to the technique which was presented in more detail in a subsequent review, the active length of the RF probe was $0-5 \mathrm{~mm} .{ }^{13}$ Its diameter was $0.5 \mathrm{~mm}$. The curved electrode tip carried a thermocouple, stimulator and a lesion generating element. The active length of the probe extended $0-5 \mathrm{~mm}$ beyond the cannula. Initial placement was by anatomical reference followed by a flouroscopic image. Final placement was determined by the patient's response to stimulus which was obtained by applying a square wave at $0.2-0.8 \mathrm{~V}$ at $50 \mathrm{~Hz}$ for $1 \mathrm{msec}$. Paresthesia or pain on stimulation revealed the location. Also, a $40{ }^{\circ} \mathrm{C}$ test lesion evoked similar response. At this point, the awake patient was given more sedation. A lesion was induced by raising the probe temperature to $60-70{ }^{\circ} \mathrm{C}$ for $70 \mathrm{sec}$. Lesions were typically $5 \times 5 \times 4 \mathrm{~mm}$. They reported $99 \%$ pain relief post-operatively.

Another recent report confirmed the imperative to adjust needle placement within the nerve by using the response to low threshold stimulation at $0.1 \mathrm{~V}$ at $50 \mathrm{~Hz}$ for $1 \mathrm{msec}^{15}$ The probe was repositioned if no response was obtained at 0.4-0.5 V. Initial settings for delivering the thermal lesion were low, at $10 \mathrm{~V}$ and $60 \mathrm{~mA}$ for $15-20 \mathrm{sec}$. Post some clinical response to this test lesion, final lesions were delivered at settings as high as $20 \mathrm{~V}$ and $100 \mathrm{~mA}$ in $40-60 \mathrm{sec}$. A separate report on deleivering $70{ }^{\circ} \mathrm{C}$ for $90 \mathrm{sec}$ for the thermal lesion noted proximity to the trigeminal of the abducens nervewhich affects the corneal response. This nerve is closest to the ophthalmic trigeminal branch, a target in about $25 \%$ of the patients treated with RF rhizotomy. They reported a case of reversible damage to the abducens. As the damage did reverse, they pose that perhaps this is a sign of preferential sensitivity to heat damage to small A delta and C fibers over more heavily myelinated fibers (i.e. the abducens.) ${ }^{14}$ 


\subsection{RF for the treatment of movement disorders}

There has been a history of clinical use of stereotactically-guided RF lesions for relief of movement disorders such as those symptoms associated with Parkinson's disease. These include dyskinesias, "on-off fluctuations", dystonia, rigidity and bradykinesia. In the case of Parkinson's disease, the hypothesis was that the symptoms of the disease were due to neuronal hyperactivity in the globis pallidus internus $\left(\mathrm{GPi}^{\mathrm{i}}\right.$. Interest in this "surgical" approach had waned with the advent of drugs which alleviated symptoms. For various reasons, the surgical technique is "back into the mainstream of treatment for otherwise intractable symptoms of Parkinson's disease" as described in a 1996 article by Favre and co-workers. ${ }^{16}$ While there is still argument as to the exact location for a therapeutically optimal thermal lesion, the target is generally taken to be GPi. The hypothetical target is approximately a $1 \times 1 \times 3 \mathrm{~mm}^{3}$ rectangular volume. ${ }^{17}$ It is generally targeted with the same thermal dose parameters as descibed above for RF rhizotomy. ${ }^{16}$

Favre presented a survey of 28 neurosurgical centers engaged in this practice of "pallidotomy" for the treatment of tremor in patients with Parkinson's disease. Magnetic resonance imaging (MRI) and computed tomography (CT) were used at the various centers to determine the target coordinates. This is a minimally invasive procedure requiring intracranial access in the absence of a suitable natural foramen. Access is achieved using a burr or twist dill to put a hole in the skull. A stereotactic frame established the entry point and trajectory with the 'standard' coordinates for the target. These were: $1-3 \mathrm{~mm}$ anterior to the midcommissural point, $18-23 \mathrm{~mm}$ lateral to the midline, and 2-6 mm inferior to the intercommisural line. Some centers reported using recording electrodes to define the pallidal base and outline the pallidum. Nearly all centers reported using stimulating electrodes to identify the target. Response to this "macrostimulation" assured suitable probe placement. Some observed patients' visual response (via the recording electrodes) as a measure of proximity to the optic tract as evoked by flashing lights. Most performed a test lesion over a reported range of $40-84$ ${ }^{\circ} \mathrm{C}$; final lesions were generally made at $75^{\circ} \mathrm{C}$ for $60 \mathrm{sec}$ (none reported treating at less than $60^{\circ} \mathrm{C}$ or for less than $30 \mathrm{sec}$ ). None of the responding centers relied on radiologic imaging alone for final determination of the target. Physiological confirmation was deemed essential. Generally, the region was treated with three lesions separated from each other along the trajectory of the probe by $2 \mathrm{~mm}$. This lesion distribution assisted in avoiding thermal damage to the optic tract. The overall lesion was intended to be a cylinder of coagulation which encompassed the medial GPi. The survey reported that the overall lesions increased in size post-operatively and were maximal on the third day. They noted ongoing controversy as to the proper location and size for a lesion. As a related note on overall lesion size, Lozano and co-workers reported lesions which were approximately $4 \times 4 \times 6 \mathrm{~mm}$ (range $80-150 \mathrm{~mm}^{3}$ ). ${ }^{17}$

In a recent study, Tsao and co-workers performed RF lesioning of the GPi with extensive pre-therapeutic mapping of the site by microelectrode recordings of cellular activity. ${ }^{18}$ The GPi was targeted initially with the same standard coordinates noted above, and approached (initially with the microelectrode) by a stereotactic frame using CT image data. By visualization of the microelectrode readings on an oscilloscope, cellular activity was correlated to physiologic observations. This refined the target to localize the lesion to the GPi as it was characterized by activity, not anatomic location. This also was used to identify the non-targeted optical tract. The lesion electrode was $1.1 \mathrm{~mm}$ diameter with a $3 \mathrm{~mm}$ exposed tip, or $1.6 \mathrm{~mm}$ diameter with a $2 \mathrm{~mm}$ tip. A thermocouple in the probe measured the temperature. The lesion probe was used for a final stimulation (to confirm no unwanted motor activity in the patient's contralateral side and no visual field 
abnormalities). The report mentions two methods for producing a lesion: one, in which 3 - 6 discrete lesions were made along a tract at $2 \mathrm{~mm}$ increments of pull-back on the probe, starting temperature of $75{ }^{\circ} \mathrm{C}$ for $60 \mathrm{sec}$ which was increased to 80,85 , and 90 with an increase also in duration over a range from 60 to $120 \mathrm{sec}$; the other method used a constant temperature of $75^{\circ} \mathrm{C}$ for $60 \mathrm{sec}$ with pull-back on the probe in 1 or $2 \mathrm{~mm}$ increments along one or two tracts. They report good MRI visualization of the postoperative lesions revealing a central necrosis and a surrounding edema. The adjustments in targeting based on microelectrode recordings did impact the placement of the lesions.

\subsection{RF for the treatment of brain tumors}

Interstitial thermal therapy is a technique in which the thermal energy source (usually a thin probe to render the therapy minimally invasive) is introduced into the targeted tissue directly. It is associated with an increase in temperature proximal to the probe: a) to levels that are sufficient to induce hyperthermia $\left(-40-50{ }^{\circ} \mathrm{C}\right)$ for which the temperatures are sustained for several tens of minutes the actual duration of which depends on the temperature, or $b)$ temperatures are raised to coagulative levels $\left(>60{ }^{\circ} \mathrm{C}\right)$ for a duration of minutes. In using RF as the thermal agent, we can refer to the therapy as radiofrequencyinduced thermal therapy (RFITT). Actually, the techniques described in 2.1 for treating trigeminal neuralgia and 2.2 for motor disorders are applications of RFITT in which the intent is to coagulate a small volume of tissue using stereotactically placed probes for a minimally invasive coagulation of small targets by probes held to $\sim 70{ }^{\circ} \mathrm{C}$ for $70 \mathrm{sec}$. Typically, tumors present targets with dimensions on the order of centimeters. The goal is often to treat this large volume with a technique such as RFITT. While RFITT has a presence in surgical literature for treating liver tumors, there is little on the targeting of larger volumes intracranially with RFITT.

Notably, a recent report from the neurosurgical literature reported on application of RFITT in an animal intracranial glioma tumor model. ${ }^{19}$ The experiment combined RFITT tissue heating and the release of a chemotherapeutic agent carried by heatsensitive liposomes. The liposomes, microscopic vesicles made of phospholipid bilayers, had been shown to be able to carry the drugs, and to release approximately $80 \%$ of their contents at or above $41{ }^{\circ} \mathrm{C}$. The heating element was a RF electrode. A separate thermocouple at the edge of the tumor provided feedback. The desired effect was to maintain the temperature at the tumor edge at $41{ }^{\circ} \mathrm{C}$ for a total of 30 minutes. The effect of this hyperthermia were seen on histology 5 days post-operatively. The results showed a higher concentration of the chemotherapeutic agent in the tumor after heating combined with liposomal drug delivery (higher than controls, heating alone, liposomes alone, and drug alone) with a delay in tumor growth. The authors suggested that the hyperthermia opened blood brain barrier (BBB) and increased the transport of drug with specific potentiation of the effect by use of the liposomes. This was not a clinical study, and there were concerns expressed about liver and spleen toxicity, but containment in the liposomes may be a factor in this and requires study.

\section{INTRACRANIAL APPLICATIONS OF LASER LIGHT}

In section 1.1.2, we noted some considerations in the applications of lasers in the brain. While indeed the $\mathrm{CO}_{2}$ has found acceptance for tissue removal, there is much to be appreciated about the neurosurgical applications of various wavelengths in the brain as evident in the extensive reviews cited in that section. ${ }^{3,7}$ The studies reviewed below are provided because they relate directly to thermal targeting of neural tissues to address 
180 / Critical Reviews Vol. CR75

clinical issues. It is evident in the studies that changes in wavelength, exposure durations and absorption profiles can profoundly influence the tissue effect and utility of laser light.

Later, in section 7.2 of this review, the topic of laser-induced thermal therapy (LITT) will be discussed in reviewing the use of MRI-guidance for thermal therapies.

\subsection{A new laser wavelength for brain tissue}

In evaluating a new laser wavelength for neurosurgical applications, Martiniuk and coworkers reported on the use of a "frequency-shifted" Nd:YAG laser with a modified wavelength of $1440 \mathrm{~nm} .{ }^{20}$ The laser was used in normal rabbit brain as a test for the wavelength to both coagulate and evaporate at the same time. The wavelength was short enough to allow transmission through a quartz fiber, but long enough to have water absorption $(\sim 10 \mathrm{x}$ that of $1064 \mathrm{~nm})$ greater than the Nd:YAG. Thus, this would have less penetration due to the increased absorption, but would have better coagulative properties than the highly absorbing $\mathrm{CO}_{2}$ laser. Their results showed a higher absorption for $1440 \mathrm{~nm}$ than for $1064 \mathrm{~nm}$ in tissue; there was more disruption with the new wavelength and less peripheral damage. They proposed that the laser had promise as a tool for resecting tumors with optimized hemostasis.

\subsection{Pulsed laser for ventricular shunt clearance}

In an in vitro experiment to model occluded ventricular shunts, Christens-Barry and coworkers reported on the use of the pulsed holmium:YAG (Ho:YAG) to break up tissue. ${ }^{21}$ In a clinical setting, the shunts are often occluded by ingrown tissues from the choroid plexus. The laser operated at $2090 \mathrm{~nm}$ which is a wavelength highly absorbed by water $(\sim 100 \mathrm{x}$ the absorption of $1064 \mathrm{~nm})$. Special fibers will transmit this wavelength. The laser emitted pulses of light 300 microseconds in duration. The strong absorption and short pulse duration provided high peak powers for a photodisruptive effect in which small, short-lived vapor bubbles were explosivley generated. The pulses were delivered in groups of $5-10$ pulses at $200-450 \mathrm{~mJ}$ per pulse through 200 and 300 micron fibers. The results showed disruption of the tissues tested which included human specimens. For shunt clearance, while there was damage to the tissues, there was no damage to the shunt material. Though, seaparately, direct hits on the material, rather than oblique hits as used for shunt clearance, did cause some slight marring of the surface.

\subsection{Contact tip for neurendoscopy}

In a clinical study of 49 patients, Vandertop and co-workers reported on the experimental application of a contact laser tip for neuro-endoscopic procedures. ${ }^{22}$ The authors expressed that while a "freebeam " use of a laser (for non-contact ablation/coagulation) is suitable for work on tumors or the choroid plexus, it may not be a controlled enough technique for neuro-endoscopy. The clinical goal is to enter the third ventricle and remove obstruction to the flow of cerebrospinal fluid (CSF). The tissues encountered are relatively white, non-pigmented, ependymal tissues and arachnoid membranes which are scattering and not highly absorbant. This necessitates the use of relatively high powers when using visible wavelengths or near IR; they report powers on the order of $15 \mathrm{~W}$ for several seconds. In such cases, tissue can undergo carbonization and be instantly become highly absorbing and the deposition of heat becomes unpredictable. Notably, in the vicinity of the third ventricle are non-targeted sensitive structures like the basilar artery. They designed a blunt ball-shaped tip, $0.8-1.0 \mathrm{~mm}$ in diameter, which was pretreated with a $90 \%$ absorbing layer of carbon particles. This was placed at the end of a 400 
micron optical fiber transmitting either $810 \mathrm{~nm}$ (diode laser) or $1064 \mathrm{~nm}$ (Nd:YAG) light. The carbon coated tip absorbs the light and becomes hot enough with low power to penetrate tissues which may poorly absorb the wavelength of light. Preclinical testing of the probe which was placed in a contact fashion had shown that the probe could penerate tissue $0.3-0.5 \mathrm{~mm}$ thick for an exposure of $0.5 \mathrm{sec}$ at $1-3 \mathrm{~W}$; the collar of damage peripheral to the penetration was $0.2-0.3 \mathrm{~mm}$ wide. Thus, the laser power was low, and the thermal effect remained proximal to the probe with short exposure times. Forty-nine patients underwent procedures for symptoms attributed to obstructed flow of CSF. The fiber was passed through a neuro-endoscope to access the targeted tissue. An overall success rate was reported for powers ranging from $1-5 \mathrm{~W}$. They reported that the desired level of control was realized in the clinical setting.

\section{INTRACRANIAL APPLICATIONS OF MICROWAVE RADIATION}

Current interest in microwaves for neurosurgical applications is to perform microwaveinduced interstitial thermal therapy (MITT). This has required the development of an interstitial probe (antenna) for tumor hyperthermia.

Salcman and Samaras reported on treating six patients with a $2450 \mathrm{MHz}$ microwave "radiator" ${ }^{23}$ The patients had failed previous therapies and the tumor regrowths were not entirely resectable. Accordingly, on craniotomy, a partial resection was performed and the un-resected portion of the tumor was treated by MITT. The $1.5 \mathrm{~mm}$ diameter probe was inserted into the residual tumor and fixed in place. The probe temperature was 'set' to a peak $45^{\circ} \mathrm{C}$ to be mainatined for $20 \mathrm{~min}$ intra-operatively. A second dose of hyperthermia was given post-operatively in the evening $\left(60 \mathrm{~min}\right.$ at $\left.45^{\circ} \mathrm{C}\right)$ and again at $48 \mathrm{hrs}$ post surgery $\left(60 \mathrm{~min}\right.$ at $\left.45^{\circ} \mathrm{C}\right)$. A $2 \mathrm{~cm}$ radius of heating was observed, and it was noted that this was twice that seen in previous experiments in the feline normal brain. That group has since followed up with added in vivo experiemnts to study the "thermal field" created by the probe. ${ }^{24}$ They described in vivo experiments in canine and feline normal brain tissue in which they observed the "thermal washout curves" in the vicinity of a MITT probe in order to determine the specific heat of brain tissue. The probe was a miniature microwave antenna operating at $915 \mathrm{MHz}$ made of semi-rigid co-axial cable with an outer diameter of $1.1 \mathrm{~mm}$ and an active length of $1 \mathrm{~cm}$.

In 1986, Roberts and co-workers reported on a phase I clinical trial to study the combined tumoricidal effect of brachytherapy (radiation seed implants) and hyperthermia in malignant gliomas. ${ }^{25}$ MITT (hyperthermia) was delivered with an array of small coaxial linear dipole antennae. ${ }^{26}$ The microwave system could generate $0-300 \mathrm{~W}$ at 915 $\mathrm{MHz}$; approximately $10 \mathrm{~W}$ was supplied per probe. Each probe had a diameter of $0.8 \mathrm{~mm}$ and an active length of $3-3.5 \mathrm{~cm}$. Based on CT images, the radiotherapy dosimetry was planned in a conventional fashion. Nylon catheters were placed intracranially according to this plan through multiple drill holes performed under local anesthesia. The day following the catheter implantation, the MITT probes were placed in the catheters and hyperthermia was given without anesthesia. Probes were generally placed $2 \mathrm{~cm}$ apart. The aim was to have the tumor periphery at $42-43{ }^{\circ} \mathrm{C}$ for $60 \mathrm{~min}$. Next, the MITT probes were replaced by iridium sources, and subsequently another dose of hyperthermia was given. In the six patients treated, some deficits were noted and difficulties intraoperatively, but it was noted that the location of the tumors were inherently problematic. The report cited a therapeutic enhancement ratio of approximately $4: 1$ for hyperthermia over radiation alone, and said the combined therapy was seen to be feasible. 
There have been reports of efforts to engineer better systems for MITT with changes in probe design. Satoh and co-workers described a microwave antenna for MITT using a helical coil technology rather than a diploe type radiator. ${ }^{27}$ They had suggested the helical design would provide a more even distribution of heat as the dipole had measurable variability along its length and a "dead" segment near the tip. The consistency of the helical design was exhibited in their experiments on normal canine brain. Moriyama and co-workers developed a cooling system for MITT probes. ${ }^{28}$ Tubing which encased the probe allowed a closed system with constant flow of saline over the probe. This cooled tissues proximal to the probe and allowed for a more uniform tissue heating to a target temperature of $43{ }^{\circ} \mathrm{C}$. This utility was demonstrated in normal monkey brain.

The helical style design antenna noted above was given a trial for use in MITT tumor therapy in 28 patients as reported by Sneed PK and co-workers in $1991 .^{29}$ There were assorted types of intracranial tumors treated which ranged in volume from $2-50 \mathrm{ml}$. The plan was to give hyperthermia at $42.5{ }^{\circ} \mathrm{C}$ for $30 \mathrm{~min}$ followed by brachytherapy with iodine-125 sources, with repeat hyperthermia. MITT was provided by an array of $1-6$ probes operating at 915 or $2450 \mathrm{Mhz}$; each $3-4 \mathrm{~cm}$ long; probes were separated at $1-2$ $\mathrm{cm}$. Extra temperature readings in the field helped to record and control temperatures. The typical arrangement was 4 probes and two multi-sensor thermometery probes. Eleven patients showed improvement, 4 showed slight improvement, and the tumors in 7 were stable; 6 showed tumor progression. They noted that the actual thermal dose required is not well understood, and that they were conservative for fear of creating to great an edematous response. But, they reported that the technology was suitable and provided well-localized heating with a relatively small number of probes.

\section{INTRACRANIAL APPLICATIONS OF ULTRASOUND}

Like most of the thermal therapies discussed in this review, ultrasound provide a source of energy which can be absorbed in tissue and thereby effectively raise tissue temperatures to therapeutic levels. Also, it can deliver focal thermal therapy interstitially: ultrasound properly coupled to tissue transmits well through the tissue and can be focused within the tissue to coagulative power densities in well-defined targetted regions. Unlike the thermal agents discussed in this review, focused ultrasound (FUS) can be a non-invasive thermal therapy. (Though, it should be noted that an ultrasound probe for interstitial applications has been reported post testing in liver, muscle and prostate. ${ }^{30}$ )

For intracranial applications, the reports to date have focused on non-invasive treatments. However, substantial absorption by the bone of the skull has presented a formidable obstacle. An early proposal for the application of "intense ultrasound" in the brain was to target the "pallido-pallidofugal complex" for hyperkinetic and hypertonic disorders (cf. studies of RFITT to target the GPi for Parkinson's disease in section 2.2 above). ${ }^{31}$ in this 1959 report, Meyers and co-workers were motivated by concerns over precise control of current ablation techniques and the lack of interactivity with the therapy to redirect treatment and better sculpt the lesion. They cited previous reports in which ultrasound produced permanent lesions in tissue and that the effect on nervous tissues had shown some selectivity with dose. In particluar, the reports showed that vascular structures were most resistant to damage, that myelin sheaths of nerve fibers were highly suscpetible, and that lesions could be made in white matter while sparing gray matter.

In that study, the ultrasound energy was produced by cut quartz crystals vibrating via the piezoelectric effect and focused by lenses and reflectors. The frequency chosen was $1 \mathrm{MHz}$ which allowed for $20 \%$ absorption per $\mathrm{cm}$ of tissue and a theoretical lesion size of $1 \mathrm{~mm}$. 
This frequency was a compromise accounting for absorption and spot size as functions of frequency. The converging ultrasound beams needed to traverse the distance to the target, without damaging the intervening tissue and to provide a small enough spot size for precision. Also, the bone of the skull had a very high absorption and acoustic impedance compared to soft tissues. These characteristics created unacceptably high temperatures at the bone and distorted that part of the beam which did transmit. This necessitated the removal of a bone flap large enough to accommodate the four converging beams of their device. Notably, sound must be coupled into the tissue through a liquid medium (degassed physiological saline); this matches the impedance of the medium off the transducer for transmission into tissue.

Alignment of the target to the focus of the ultrasound was accomplished using cerebral landmarks and x-rays. A lesion was expected from each $2.3-3.0 \mathrm{sec}$ exposure; a lesion smaller than the target volume. After each exposure, clinical physiological response was observed until a therapeutically beneficial result was obtained. Overall the treatments were deemed successful. Notably, the system was complex and the procedure time consuming.

In a 1981 report to address the issue of transmission though bone for cranial applications, Fry and co-workers devised an experiment to create lesions in vivo in a feline brain through a section of human skull. ${ }^{32}$ They used a $12.7 \mathrm{~cm}$ diameter circular transducer as opposed to converging beams from a few singular sources. The transducer operated at 1 $\mathrm{MHz}$ with a focal distance of $13 \mathrm{~cm}$ and had a $2-3 \mathrm{~mm}$ beam diameter at the focus. They reported having created well-defined lesions in the thalamus with no evidence of severe beam distortion. Also, in some cases, there was evidence of lesions created in the white matter with sparing of gray matter. They concluded that the results were promising and that tissue could be efffectively ablated through bone.

In a 1998 report, Hynynen and Jolesz propose a solution to the problem of the skull transmission and distortion of ultrasound for intracranial application of FUS. ${ }^{33}$ They cite previous reports of experiments showing strong attenuation by bone $(10 \mathrm{~dB}$ at $0.5 \mathrm{Mhz}$, and $20 \mathrm{~dB}$ at $1.5 \mathrm{Mhz}$ ) which, again, not only creates unwanted thermal effects near the skull but also interferes with the planned energy distribution at the targeted deep tissue. They cite an additional human study on FUS in which it had been necessary to remove the intervening bone. ${ }^{34}$ They noted that there is still some transmission through bone, and that the loss can be accommodated by focusing. A problem is that the focus can shift from the predicted location due to variations in the skull thickness and refraction. The solution is to adjust the focus by applying corrections to the phase of the ultrasound source. They drove arrays of transducer elements which could be independently controlled to adjust the phase; this refocused the beam after distortion by the skull. The arrays tested operated at $0.6 \mathrm{MHz}$ and $1.58 \mathrm{MHz}$. The phased array was shown to refocus albeit with diminished power ( $5 \%$ of initial value) in the presence of the skull segment.

In an in vitro experiment, Akiyama and co-workers used FUS in researching the use of this energy source transcranially to break up intracranial blood clots. ${ }^{35}$ An ultrasound probe was operated at $211.5 \mathrm{kHz}$ and $1.03 \mathrm{MHz}$. Using human specimens, they reported suitable transmission through temporal bone specimens. They were able to disrupt thrombolysis in the presence of urokinase (a thrombolytic agent). The mechanism of the effect was not clear and it was speculated as to whether there was a thermal effect or a mechanical cavitation which disrupted the fibrin network. Though, they proposed the treatment with US did help to permeate the thrombus with the thrombolytic agent and that this may be clinically useful. 


\section{INTRACRANIAL APPLICATIONS OF CRYOGENS}

There is little in the neurosurgical literature on cryotherapy for intracranial applications. Of course, cryogens and freezing probes for interstitial applications have been developed. By using temperatures as low as $-180^{\circ} \mathrm{C}$, in various cycles of freezing and thawing, a cytotoxic effect has been observed. This is well-documented in cryobiology literature. Cells undergo dehydration and rupturing due to osmotic pressure gradients; and additional cell kill is attributed to vascular destruction with subsequent nutritional deprivation. As there are interstitial probes available for cryotherapy (and these probes become smaller and customized with time) there may indeed be room for minimally invasive cryo-induced thermal therapy (CITT) in the brain for tissue ablation.

An early report of interest in CITT was reported by Rowbotham and co-workers. ${ }^{36}$ In a 1959 Lancet article, they described clinical use of a "cooling cannula" of their design used clinically to treat gliomas. They were motivated by inadequate results of surgical excision and the resistance to x-ray irradiation by some tumor sub-types. Further, they looked for a solution which more selectively targeted the tumor. Other hypothermic therapies relied on excessive cooling for the whole body or too large a portion of the head. Their cooling cannula was designed to provide "intense cold" to a small area of the brain. The cannula was about 8 inches long and the outer diameter of the closed, bluntended steel tube was 0.2 in $(5 \mathrm{~mm})$. Along the outside of the cannula was welded a channel to hold a thermocouple which would provide a measure of the temperature at the tip. Inside, coaxial with the outer tube was a 0.1 in steel tube which carried $95 \%$ alcohol as a "circulating fluid" which was made cold by passing it through a "freezing mixture" of solid carbon dioxide. This set the tip to $-20^{\circ} \mathrm{C}$. On three patients the cannula was inserted "into what was judged to be the center of the tumor." Treatment was given as a cooling period which lasted for $30 \mathrm{~min}$. Generally, the report stated to have established the safety of the procedure. It is likely the iceball was not much larger than the probe itself; temperatures $2 \mathrm{~cm}$ away were reduced from body temperature by only a few degrees.

In a technical advance for intracranial applications, in 1961 Cooper and co-workers reported on developing a cannula through which circulated liquid nitrogen. ${ }^{37}$ This provided a tip temperature of $-196{ }^{\circ} \mathrm{C}$ and was designed to create a lesion $8 \mathrm{~mm}$ in diameter. The target was the basal ganglia to treat motor disorders (hyperkinesia, tremor, rigidity). They noted the need for a "clinicophysiologic type of procedure" - to produce a reversible test lesion at the target site, observe the effects on the awake patient and then deliver the "permanent destructive lesion." While some details were provided on the device, there was no report of implementation on living tissue.

More recently, in 1993 Gilbert and co-workers reported results of an in vivo experiment on rabbit brains. ${ }^{38}$ They developed a $4 \mathrm{~mm}$ diameter pyrex probe through which flowed liquid nitrogen. The probe was placed in contact with the brain tissue on craniotomy and the cooling sustained until the frozen region penetrated $5 \mathrm{~mm}$ into tissue (through the cerebral cortex to superior border of thalamus). This took approximately 8 minutes, and formed a broad lesion approximately $2 \mathrm{~cm}$ in diameter.

\section{MRI GUIDANCE FOR INTRACRANIAL THERMAL THERAPIES}

The motivation for minimally invasive therapy is reduced trauma to non-targeted tissues in order to have faster healing. The crux of performing minimally invasive therapy is control. The need for control is unfufilled in some modalities. 
The solution by which to provide control is two fold: 1) prescription - control arises from the principles discussed in the introduction to this review - a synergy of engineering of the agent and and understanding of the target; 2) feedback - proper intra-operative visualization of the surgical field. In all of the minimally invasive techniques discussed, factors in failure, partial treatment or over-treatment are dosimetry (prescription) and monitoring (feedback).

\subsection{Advances toward MRI-guided intracranial CITT}

To appreciate the principles of image-guidance for control of interstitial thermal therapies, consider the Gilbert report cited at the end of the previous section. Experimental cryotherapy was performed on the cortex of a living rabbit using a liquid nitrogen probe. ${ }^{38}$ The probe was placed on the surface of the brain through a hole in the skull. The targeted tissue was the full thickness of the cortex inferior to the probe; the requirement was that the thalamus on the other side of the cortex be spared. These structures were not visible from the surface. MRI provided the visualization of the tissues and of the interaction. MRI is a non-invasive radiologic technique with notably high contrast for soft tissues and inherent sensitivity under certain protocols for visualization of thermal events. In this case, three types of imaging protocols (sequences) were used: a $\mathrm{Tl}$ weighted (T1) spin echo sequence, a T2-weighted (T2) spin echo sequence, and a T1weighted spoiled gradient recalled echo (SPGR) sequence. Imaging was performed on a small bore, non-clinical imaging unit with a field strength of 2.35 Tesla (T) and a bore of $30 \mathrm{~cm}$. The anatomy of the cortex and underlying thalamus were evident in coronal slices (each $3 \mathrm{~mm}$ thick) by all three sequences (though with different contrast for different structures). The intra-operative visualization of the freezing process was seen on $\mathrm{T} 1$ and SPGR imaging. The advance of the ice in tissue was seen as a black, hypointense zone in contrast to the adjacent normal tissue. This decrease in signal was due to the freeze which crystallizes the tissue and 'zeros' the relaxation time associated with the water protons allowing no observable signal in the imaging process. Post-operative contrast-enhanced $\mathrm{T} 1$ and $\mathrm{T} 2$ imaging post-operatively showed evidence of disruption of the BBB and vasculature as well as edema formation. Previous reports had presented similar results in providing preclinical evidence of MRI to monitor thermal therapies in tissue and provide feedback for the control. ${ }^{39-42}$

A difficulty for the application of MRI-guided CITT has been the availability of suitable probes, probes which are MRI-compatible. ${ }^{43,44}$ Notably, the probes used in the studies cited above were made of stainless steel or pyrex. ${ }^{36-38}$ The stainless steel probes would create a substantial susceptability artifact in the MR images so as to obscure the anatomy. The glass pyrex probe would not have this problem, but would not be sufficiently robust for clinical use. Contemporary probes used in general surgery are stainless steel and are large $(\sim 4 \mathrm{~mm}$ diameter). Also, the clinical cryotherapy units are typically not compatible with the high magnetic fields. Cryotherapy devices have recently been adapted for use in the MRI environment using nitrogen or argon via the Joule-Thompson gas expansion effect for cooling. MR-compatible probes on the order of $1-2 \mathrm{~mm}$ have been manufactured for non-intracranial applications (prostate, liver). Also, a recent report in the German literature presented intra-operative imaging of in vivo experiments using a 2.7 $\mathrm{mm}$ diameter MR-compatible cryotherapy probe in normal porcine brain. ${ }^{45}$

\subsection{MRI-guided intracranial LITT}

MRI-guided LITT of brain tissues has been studied and implemented clinically since first proposed. ${ }^{39,46-51}$ Realtively deeply penetrating red and near infrared laser light can be 
transmitted down quartz optical fibers with diameters as small as $0.2 \mathrm{~mm}$. The fibers are MRI-compatible and present no susceptability artifact in the images. The fibers can be manufactured 10-12 m long so that, even though the laser unit may not be in the MRI procedure room, the light can be transmitted to the surgical field. Thus, laser light was readiliy implemented into the MRI environment.

In current use, intracranial targets are tumors or vascular malformations ranging from 1 - 4 $\mathrm{cm}$ in diameter. In order to create a large enough volume of cell kill, various strategies can be used: single bare fibers $(0.6-1.0 \mathrm{~mm}$ diameter) with repositioning as needed, multiple bare fibers, or diffusing tip fibers.

Important to the implementation of LITT has been the sensitivity of MRI to changes in temperature. We have used one of two types MRI techniques for thermal monitoring: ${ }^{49-5 !}$

- Tl fast spin echo (T1 FSE) sequence; TR/TE $=400 / 18 \mathrm{msec}$; echo train length of 4; $5 \mathrm{~mm}$ slice thickness; $22 \mathrm{~cm}$ square field of view; $256 \times 128$ matrix. An image with this sequence is acquired in $13 \mathrm{sec}$.

- Spoiled gradient recalled echo (SPGR) sequence; TR/TE $=55 / 14 \mathrm{msec} ; 20^{\circ}$ flip angle; $4 \mathrm{~mm}$ slice thickness; $32 \mathrm{~cm} \times 24 \mathrm{~cm}$ field of view; $256 \times 128$ matrix. Image acquisition per slice is $5 \mathrm{sec}$.

These MRI pulse sequences also provide images in a time frame suitable for the devloping lesion. The TI FSE can acquire a full field-of-view image in $13 \mathrm{sec}$; the SPGR can do so in $5 \mathrm{sec}$. The latter pulse sequence provides data on the change in the phase of the chemical shift which is a temperature senstive parameter and from which temperature maps can be derived. ${ }^{50,52,53}$ The greyscale MRI images are supplemented with computer processing to enhance the visualization of the information in the images. ${ }^{49-51.54,55}$

While considerable clinical experience has been gained on conventional closed-bore MRI scanners. An essential development for our program was the introduction of an interventional 'open' MRI scanner. ${ }^{56-58}$ Two key elements of such a system allow for direct access to the patient by health care personnel and dynamic control of the image plane by the physician. The latter assists in surgical planning and targetting of the tumor. Siefert and co-workers recently reported on neurosurgical applications of a similar system. In that report, they refer to having treated three patients with LITT with MRI-guidance. ${ }^{59}$

\subsection{MRI-guided intracranial RFITT}

RF technology has been considered for use in the MRI environment. However, the technical challenges to making a device operate in the MRI environment have been substantial. The problems of RF interference with the MRI images and the materials choice for compatible probes is being solved at present and prototype systems exist. While the probes are designed currently for abdominal use, modifications for intracranial applications are possible as indications warrant.

While not used intra-operatively, MRI has contributed to RFITT in evaluating thermal lesions post-operatively. Tomlinson and co-workers imaged 21 patients who had undergone RF thalotomy for tremor control. ${ }^{60}$ Single lesions were made with a $1.6 \mathrm{~mm}$ diameter electrode with a $3 \mathrm{~mm}$ active length. The tip had been heated to $78{ }^{\circ} \mathrm{C}$ for 60 $\mathrm{sec}$; sometimes with a second 'dose.' Post-operative MRI assessed the lesion's development over time. With both $\mathrm{Tl}$ and $\mathrm{T} 2$ imaging, "hemorrhagic necrosis" and edema were clearly identified and characterized the lesion. It also provided a measure by which to confirm the success of targeting the thalamus. 
In a 1995 report, DeSalles and co-workers performed RFITT for thalotomy and pallidotomy in treating 11 patients for severe tremor, chronic pain, dystonia ${ }^{61}$ They cited others who had used MRI to assess RF-induced lesions. They focused on the initial 72 hours post-therapy. MRI images were taken pre-operatively and the targeting of the lesion was done with a stereotactic frame and the MRI images. The surgery involved $4+/-2$ RF lesions at $80{ }^{\circ} \mathrm{C}$ for $60 \mathrm{sec}$ from a $2.5 \mathrm{~mm}$ long probe. They did T1, T2 and contrastenhanced images. The lesion was evident immediately after therapy with variations in MRI appearance per the different sequences over time. In a study of MRI of RFITTtreated patients for pallidotomy, Krauss and co-workers observed 36 patients 1-3 days post-operatively with follow-up out to six months. ${ }^{62}$ Zones of effect were evident. MRI assessed the mean volume of the middle zone of tissue change which represented hemorrhagic necrosis at $44 \mathrm{~mm}^{3}$; if including the edemamatous response, this volume measurement extended to $262 \mathrm{~mm}^{3}$. MRI revealed additional edema spreading toward the internal capsule and optic tract. At 6 months, total lesions measured $\sim 22 \mathrm{~mm}^{3}$. The report makes no correlation between lesion size \& location and clinical outcome. The study did use the MR imaging to confirm lesion overlap with the GPi. Overall, the thermal lesions (guided to the target by physiologic response/monitoring) were entirely or mostly in the GPi.

\subsection{MRI-guided intracranial FUS}

There has been considerable effort in the use of FUS for non-invasive image-guided therapy. Current clinical tests are ongoing for use in the breast for both benign and malignant disease. As mentioned in section 7 above, there have been advances in the approach to targeting in the brain which compensate for the difficulties of sound transmission through the skull. ${ }^{33}$ Further, in vivo studies in experimental animal models have been used to monitor the effects of FUS in normal brain tissues. ${ }^{63,64}$ It is certainly appealing that a solution to the problem of focusing ultrasound through the skull would make this non-invasive therapy available for clinical research in human disease.

\section{CLOSING COMMENTS}

We have reviewed the intracranial use of several thermal agents. The presentation was intended to illustrate the variety of thermal applications which are in clinical use or being researched. From a synopsis of each of certain reports, highlights of the clinical goals and therapeutic methods are discerned. It is evident that the number of 'current' intracranial applications in humans of the thermal agents discussed is limited. And yet, while the number of applications is limited, the breadth of applications is substantial. i.e. The principle interstitial applications (i.e., with some record of clinical use in the brain RFITT, LITT, MITT) are targeted at tissue volumes which are range from less than one half of one cubic centimeter (GPi) to several centimeters in diameter (tumor). The spectrum of possible therapies is from 'functional' neurosurgery to tumor ablation.

While RF has been successful in minimally invasive treatment of disorders which require small thermal lesions, all of the agents, as they are engineered to perform interstitial thermal therapy especially to target large tissue volumes in the brain will require image-guidance. As seen in the work highlighted here, the modailites share common requirements as to defining and targeting a lesion and obtaining sufficient feedback to control and optimize the thermal effect. We expect that, as techniques for improved image-guidance for such minimally invasive therapies are available, particularly MRI, there will be greater confidence with which to approach the range of targets with the 
range of thermal agents. If clinically proven, such techniques could share in the approaches with which to manage disease, complementing the surgeon's expertise.

\section{REFERENCES}

1. Malis LI. "Electrosurgery," J Neurosurg 1996; 85:970-975.

2. J Boulnois. "Photophysical processes in medical lasers," Lasers Med Science $1986 ; 1: 47-66$.

3. Jain KK. "Lasers in neurosurgery: a review," Lasers Surg Med 1983; 2:217230.

4. Svaasand LO, Boerslid $\mathrm{T}$, Oeveraasen M. "Thermal and optical properties of living tissue: application to laser-induced hyperthermia," Lasers Surg Med $1985 ; 5: 589-602$.

5. Jacques SL, Prahl SA. "Modeling optical and thermal distributions in tissue during laser irradiation," Lasers Surg Med 1987; 6:494-503.

6. Wyman D, Wilson B, Adams K. "Dependence of laser photocoagulation on interstitial delivery parameters," Lasers Surg Med 1994; 14:59-64.

7. Krishnamurthy S, Powers SK. "Lasers in Neurosurgery," Lasers Surg Med 1994; 15:126-167.

8. Skinner M, Iizuka MN, Kolios MC, Sherar MD. "A theoretical comparison of energy sources - microwave, ultrasound and laser - for interstitial thermal therapy," Phys Med Biol 1998; 43:3535-3547.

9. Sweet WH, Wepsic JG. "Controlled thermocoagulation of trigeminal ganglion and rootlets for differential destruction of pain fibers: part 1: trigeminal neuralgia," J Neurosurg 1974; 39:143-156.

10. Hori T, Fukuskima $T$, Terao H, Takakura K, Sano K. "Percutaneous radiofrequency facial nerve coagulation in the management of facial spasm," $J$ Neurosurg 1981; 54:655-658.

11. Cosman ER, Nashold BS, Bedenbaugh P. "Stereotactic radiofrequency lesion making," Appl Neurophysiol 1983; 46:160-166.

12. Taha JM, Tew JM. "Comparison of surgical treatemtns for trigeminal neuralgia: reevaluation of radiofrequency rhizotomy," Neurosurgery 1996; 38:865-871.

13. Taha JM, Tew JM. "Treatment of trigeminal neuralgia by percutaneous radiofrequency rhizotomy," Neurosurgery Clinics of N America 1997; 8:31-39.

14. Harrigan MR, Chandler WF. "Abducens nerve palsy after radiofrequency rhizolysis for trigeminal neuralgia: case report," Neurosurgery 1998; 43:623625.

15. Nugent GR. "Radiofrequency treatment of trigeminal neuralgia using a cordotomy-type electrode," Neurosurgery Clinics of N America 1997; 8:41-52.

16. Favre J, Taha JM, Nguyen TT, Gildenberg PL, Burchiel KJ. "Pallidotomy: a survey of current practice in North America," Neurosurgery 1996; 39:883-890.

17. Lozano A, Hutchison W, Kiss Z, Tasker R, Davis K, Dostrovsky J. "Methods for microelectrode-guided posteroventral pallidotomy," J Neurosurg 84:194-202.

18. Tsao K, Wilkinson S, Overman J, Koller WC, Batnitzky S, Gordon MA. "Pallidotomy lesion locations: significance of microelectrode refinement," Neurosurgery 1998; 43:506-12.

19. Kakinuma K, Tanaka R, Takahashi H, Watanabe M, Nakagawa T, Kuroki M. "Targeting chemotherapy for malignant brain tumor using thermosensitive liposome and localized hyperthermia," J Neurosurg 1996; 84:180-184.

20. Martiniuk R, Bauer JA, McKean JD, Tulip J, Mielke BW. "New longwavelength Nd:YAG laser at 1.44 micron: effect on brain," J Neurosurg 1989; 70:249-56. 
21. Christens-Barry WA, Guarnieri M, Carson BS. "Fiberoptic delivery of laser energy to remove occlusions from ventricular shunts: technical report,"

Neurosurgery 1999; 44:345-349.

22. Vandertop WP, Verdaasdonk RM, van Swol CF. "Laser-assisted neuroendoscopy using a neodymium-yttrium aluminum garnet or diode contact laser with pretreated fiber tips," J Neurosurg 1998; 88:82-92.

23. Salcman M, Samaras GM. "Interstitial microwave hyperthermia for brain tumors: results of a phase-I clinical trial," Journal of Neuro-Oncology 1983 1:225-236.

24. Salcman M, Moriyama E, Elsner HJ, Rossman H, Gettleman RA, Neuberth G, Corradino G. "Cerebral blood flow and the thermal properties of the brain: a preliminary analysis," J Neurosurg 1989; 70:592-59.

25. Roberts DW, Coughlin CT, Wong TZ, Fratkin JD, Douple EB, Strohbehn JW. "Interstitial hyperthermia and iridium brachytherapy in treatment of malignant glioma: a phase I clinical trial," J Neurosurgery 1986; 64:581-587.

26. Coughlin CT, Wong TZ, Strohbehn JW, Colacchio TA, Sutton JE, Belch RZ, Douple EB. "Intraoperative interstitial microwave-induced hyperthermia and brachytherapy," Int J Radiation Oncololgy Biol Phys 1985; 11:1673-1678.

27. Satoh T, Seilhan TM, Stauffer PR, Sneed PK, Fike JR. "Interstitial helical coil microwave antenna for experimental brain hyperthermia," Neurosurgery 1988; 23:564-569.

28. Moriyama E, Matsumi N, Shiraishi T, Tamiya T, Satoh T, Matsumoto K, Furuta T, Nishimoto A. "Hyperthermia for brain tumors: improved delivery with a new cooling system," Neurosurgery 1988; 23:189-195.

29. Sneed PK, Stauffer PR, Gutin PH, Phillips TL, Suen S, Weaver KA, Lamb SA, Ham B, Prados MD, Larson DA, Wara W. "Interstitial irradiation and hyperthermia for the treatment of recurrent malignant brain tumors," Neurosurgery 1991; 28:206-215.

30. Deardorff DL, Diederich CJ, Nau WH. "Ultrasound applicators with internal cooling for interstitial thermal therapy," Proceedings of the SPIE BiOs '99 International Biomedical Optics Symposium, 23-29 January 1999, San Jose CA. Conference Thermal Treatment of Tissue with Image Guidance \#3594-05.

31. Meyers R, Fry WJ, Fry FJ, Dreyer LL, Schulz DF, Noyes RF. "Early experiences with ultrasonic irradiation of the pallidofugal and nigral complexes in hyperkinetic and hypertonic disorders," J Neurosurg 1959; 16:32-54.

32. Fry FJ, Goss SA, Patrick JT. "Transkull foacl lesions in cat brain produced by ultrasound," J Neurosurg 1981; 54:659-663.

33. Hynynen K, Jolesz FA. "Demonstration of potential noninvasive ultrasound brain therapy through an intact skull," Ultrasound in Med \& Biol 1998; 24:275-283.

34. Guthkelch AN, Carter LP, Cassady JR, Hynynen K, Iacono RP, Johnson PC, Obbens EA, Roemer RB, Seeger JF, Shimm DS, Stea B. "Treatment of malignant brain tumors with focussed ultrasound hyperthermia and radiation: results of a phase I trial," $J$ Neuro-oncol 1991; 10:271-284.

35. Akiyama M, Ishibashi T, Yamada T, Furuhata H. "Low-frequency ultrasound penetrates the cranium and enhances thrombolysis in vitro," Neurosurgery 1998; 43:828-832.

36. Rowbotham GF, Haigh AL, Leslie WG. "Cooling cannula for use in the treatment of cerebral neoplasms," Lancet 1959; 1:12-15.

37. Cooper IS, Lee A St J. "Cryothalamectomy - hypothermic congelation: a technical advance in basal ganglia surgery," J Amer Geriatrics Soc 1961; 9:714718. 
38. Gilbert JC, Rubinsky B, Roos MS, Wong STS, Brennan KM. "MRImonitored cryosurgery in the rabbit brain," Magnetic Resonance Imaging 1993; 11:1155-1164.

39. Jolesz FA, Bleier AR, Jakab P, Ruenzel PW, Huttl K, Jako GJ. "MR imaging of laser-tissue interactions," Radiology 1988; 168:249-253.

40. Matsumoto R, Oshio K, Jolesz FA. "Monitoring of laser and freezing-induced ablation in the liver with tl-weighted MR imaging," JMRI 1992; 2:555-562.

41. Cline HE, Schenck JF, Walkins RD, Hynynen K, Jolesz FA. "Magnetic resonance guided thermal surgery," Magn Reson Med 1993; 30:98-106.

42. Matsumoto R, Mulkern RV, Hushek SG, Jolesz FA. "Tissue temperature monitoring for thermal interventional therapy: comparison of $t l$-weighted $M R$ sequences," JMRI 1993; 4:65-70.

43. Jolesz FA, Morrison PR, Koran SJ, et al. "Compatible instrumentation for intra-operative MRI: expanding resources," JMRI 1998; 8:8-11.

44. Silverman SG, Jolesz FA, Newman RW, Morrison PR, Kanan AR, Kikinis R, Schwartz RB, Hsu L, Koran SJ, Topulos GP. "Design and implementation of an interventional MR imaging suite," AJR 1997; 168:1465-1471.

45. Tacke J, Speetzen R, Schorn R, Glowinski A, Grosskortenhaus S, Adam G, Rasche V, Rau G, Gunther RW. "Experimental MRI-controlled cryotherapy of the brain with almost real-time imaging by radial k-space scanning," Rofo Fortschritte auf dem Geb der Rontgenstrahlen Neuen Bild Verf. 1999; 170:214217.

46. Fan M, Ascher PW, Schrottner O, Ebner F, Germann RH, Kleinert R. "Interstitial 1.06 Nd:YAG laser thermotherapy for brain tumors under real-time monitoring of MRI: experimental and phase I clinical trial," J Clin Laser Med Surg 1992; 10:355-361.

47. Schober R, Bettag M, Sabel M, Ulrich F, Hessel S. "Fine structure of zonal changes in experimental Nd:YAG laser-induced interstitial hyperthermia," Lasers Surg Med 1993; 13:234-241.

48. Kahn T, Bettag M, Ulrich F, et al. "MR-imaging guided laser-induced interstitial thermotherapy in cerebral neoplasm," J Comput Assist Tomogr 1994; 18:519-532.

49. Hata N, Morrison PR, Kettenbach J, Kikinis R, Jolesz FA. "Computer-assisted intra-operative MRI monitoring of interstitial laser therapy in the brain: a case report," SPIE J Biomed Optics 1998; 3:304-311.

50. Kettenbach J, Silverman SG, Hata N, et al. "Monitoring and visualization techniques for MR-guided laser ablations in an open MR system," JMRI 1998; 8:933-943.

51. Kettenbach J, Kuroda K, Hata N, Morrison P, McDannold NJ, Gering D, Saiviroonporn P, Zientara GP, McL.Black P, Kikinis R, Jolesz FA. "Laserinduced thermotherapy of cerebral neoplasia under MR tomographic control," Min Invas Ther \& Allied Technol 1998; 7(6):589-598.

52. Kuroda K, Suzuki Y, Ishihara Y, Okamoto K, Suzuki Y. "Temperature mapping using water proton chemical shift obtained with 3D-MRSI: feasibility in vivo," Magn Reson Med 1996; 35:20-29.

53. Cline HE, Schenck JF, Watkins RD, Hynynen K, Jolesz FA. "Magnetic resonance guided thermal surgery," Magn Reson Med 1993; 30:98-106.

54. Wyman DR, Wilson BC, Malone D. "Medical imaging systems for feedback control of interstitial laser photocoagulation," Proceedings SPIE 1992; 80:890902. 
55. Zientara GP, Saiviroonporn P, Morrison PR, Fried MP, Hushek SG, Kikinis $\mathrm{R}$, Jolesz FA. "MRI-monitoring of laser ablation using optical flow," JMRI 1998; 8:1306-1318.

56. Schenck JF, Jolesz FA, Roemer PB et al. "Superconducting open-configuration MR imaging system for image-guided therapy," Radiology 1995;195:805-814.

57. Black PML, Moriarty T, Alexander E, et al. "Development and implementation of intraoperative magnetic resonance imaging and its neurosurgical applications," Neurosurgery 1997; 41:831-845.

58. Morrison PR, Black P McL, Jolesz FA. "Technical Considerations for Nd:YAG Intracranial LITT in an iMRI Unit," Proceedings of the SPIE BiOs '99 International Biomedical Optics Symposium, 23-29 January 1999, San Jose CA. Conference on Thermal Treatment of Tissue with Image Guidance \#359423.

59. Seifert V, Zimmermann M, Trantakis C, Vitzthum HE, Kuhnel K, Raabe A, Bootz F, Schneider JP, Schmidt F, Dietrich J. "Open MRI-guided neurosurgery," Acta Neurochir 1999; 141:455-64.

60. Tomlinson FH, Jack CR Jr, Kelly PJ. "Sequential magnetic resonance imaging following stereotactic radiofrequency ventralis lateralis thalamotomy," $J$ Neurosurg 1991 74:579-84.

61. DeSalles AAF, Brekhus SD, DeSouza EC, Behnke EJ, Farahani K, Anzai Y, Lufkin R. "Early post-operative appearance of radiofrequency lesions on magnetic resonance imaging," Neurosurgery 1995; 36:932-936.

62. Krauss JK, Desaloms JM, Lai EC, King DE, Jankovic J, Grossman RG. "Microelectrode-guided posteroventral pallidotomy for treatment of Parkinson's disease: postoperative magnetic resonance imaging analysis," J Neurosurg 1997; 87:358-367.

63. Hynynen K, Vykhodtseva NI, Chung AH, Sorrentino V, Colucci V, Jolesz FA. "Thermal effects of focused ultrasound on the brain: determination with MR imaging," Radiology 1997; 204:247-253.

64. Morocz I, Hynynen K, Gudbjartsson H, Peled S, Colocci V, Jolesz FA. "Brain edema development after MRI-guided focused ultrasound treatment," JMRI 1998; 8:136-142.

\footnotetext{
' 'double quotes indicate quotes from text"; 'single quotes for authors' emphasis.'
} 